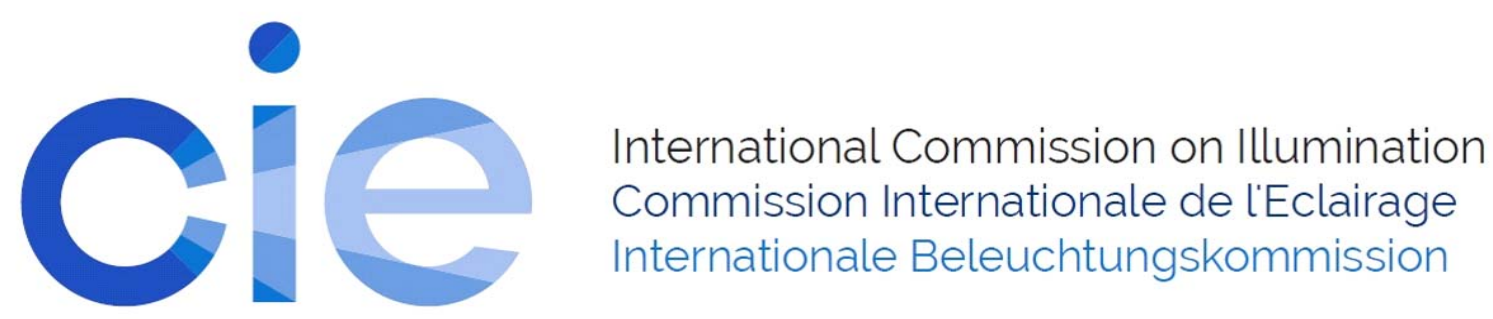

P0151

\title{
BUILDING INFORMATION MODELING BASED ARCHITECTURAL LIGHT EMITTING DIODE LIGHTING DESIGN: A PROPOSAL \\ Wu Yuting et al.
}

DOI 10.25039/x46.2019.PO151

from

CIE x046:2019

Proceedings

of the

29th CIE SESSION

Washington D.C., USA, June 14 - 22, 2019

(DOI 10.25039/x46.2019)

The paper has been presented at the 29th CIE Session, Washington D.C., USA, June 14-22, 2019. It has not been peer-reviewed by CIE.

(c) CIE 2019

All rights reserved. Unless otherwise specified, no part of this publication may be reproduced or utilized in any form or by any means, electronic or mechanical, including photocopying and microfilm, without permission in writing from CIE Central Bureau at the address below. Any mention of organizations or products does not imply endorsement by the CIE.

This paper is made available open access for individual use. However, in all other cases all rights are reserved unless explicit permission is sought from and given by the CIE.

CIE Central Bureau

Babenbergerstrasse 9

A-1010 Vienna

Austria

Tel.: +4317143187

e-mail: ciecb@cie.co.at

www.cie.co.at 


\title{
BUILDING INFORMATION MODELING BASED ARCHITECTURAL LIGHT EMITTING DIODE LIGHTING DESIGN: A PROPOSAL
}

\author{
Wu, Y.T., Wang, A.Y., Wang, L.X., Yu J. \\ School of Architecture of Tianjin University, Tianjin, CHINA \\ Tianjin Key Laboratory of Architectural Physics and Environmental Technology \\ wayway@tju.edu.cn
}

DOI 10.25039/x46.2019.PO151

\begin{abstract}
Light-emitting diode (LED) is considered to be one of the feasible light source in the future. The combination of LED and architecture puts forward new requirements for Building Lighting Integration (BLI) design. This paper is concerned with the development of the BLI design software that based on Building Information Modelling (BIM) technology. Application Programming Interface (API) and Format Conversion of Information (FCI) are believed as the two main technologies during this process. In the development process, the two main technical problems with Revit as the core part are discussed. Design suggestions were given for form and lamp component library of the BLI design software that need to be designed.
\end{abstract}

Keywords: Building information modelling, Building lighting integration, Design software

\section{Introduction}

Building information modelling (BIM) technology is a vital innovation in the field of construction engineering. With the powerful digital technology, most of the information related to the building construction is involved including architecture, building structure, Heating, Ventilation and Air Conditioning (HVAC), electricity, water supply and drainage system, etc.(Pezeshki and Ivari, 2018). At the same time, the information may cover the whole life cycle of a building project from planning, design, construction, operation even to abandonment (Santos et al., 2019). This technology seems complex and costly, but BIM can greatly improve work efficiency, especially in the field of architecture design and construction management. So, the BIM technology is becoming popular all over the world. As a part of architectural design, architectural lighting naturally should be involved in the application of BIM technology.

Light emitting diode (LED) is considered to be one of the most feasible future light source. Its features of high efficiency and small size make it very suitable for the integration of light source and architecture (Santos et al., 2019), which is defined to be Building Lighting Integration (BLI) design. In this BLI design process, LED light sources are no longer exist independently, but combined with building components, such as acoustic components, or HVAC components and so on. In this way, it is clear that the design efficiency can be improved, and the comfortable and healthy lighting environment can be realized through the comprehensive design (Hassan et al., 2015).

In order to realize the idea of Building Lighting Integration in the future, the BIM technology was taken into consideration. Actually, the former may become a new part of the BIM of a building. However, the following objectives of the BLI design software that to be developed should be accomplished, including:

- Integrative design of building lighting, that is, building and storing all information, as the model information, of building and lighting in BIM system;

- Lighting calculation, that is to realize the calculation of lighting information and export the results;

- Verification of lighting design, that is to realize the return and evaluation of the information of lighting calculation results. 


\section{Main technical means in BIM}

In order to develop the BLI design software, the focus will be on two main technical means that used in BIM, which are Application Programming Interface Technology (APIT) and Format Conversion of Information Technology (FCIT).

\subsection{Application Programming Interface Technology (APIT)}

Application Programming Interface (API) is a bridge for BIM system software developers to integrate the third-party applications (plug-ins) into existing related software (Pärn and Edwards, 2017), which affects the information exchange and program development of the entire BIM system. APIT is mainly applied in three aspects, i.e. information transmission, program connection and program development. Information transmission means that the information inside software is extracted by API and transmitted to the place where it is needed. Program connection means that API connect the relevant software exists in BIM system with a third-party application program (plug-in) in where the certain calculation is processed. Program development refers to that the developed third-party application program (plug-in) must be API based.

The BIM system is based on the core modelling software through which other data processing software of BIM system exchanges information to realize collaborative design. Revit is one of the most widely used core modelling software for BIM system. Revit version 1.0 was released in 2000. By 2005, the development of plug-ins and API have begun in Autodesk Revit 8.0. Over the past decade, Revit API has developed rapidly and became more and more diverse. The functionality of the API has been greatly improved. From the beginning, only objects in the document can be accessed, to the later versions, the function of creating families has been added. The functions of the latest version which is Revit 2019 are shown in Figure 1.

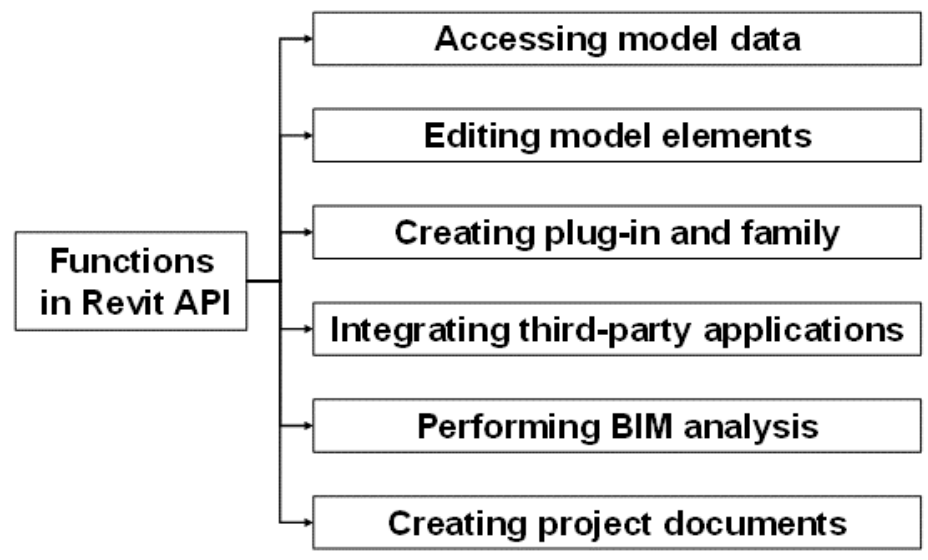

Figure 1 - Functions of Revit2019 API

The function of the Revit API is realized by the assemblies of Revit API.dll and Revit APIUI.dll (Zotkin et al., 2016), which need to be selected simultaneously in the process of transferring information and connecting programs. Because the limitations of assemblies in Revit API, the transferred information and the development of the connection program are also limited, which may result in missing or insufficient of information and some processing functions. For example, when APIT is used to transmit information, i.e. to extract information through Revit $\mathrm{API}$, it is impossible to extract the rendering appearance information of materials through Revit API. Therefore, the rendering function that provided in the form of Revit plug-in and some computing functions of lighting software cannot be used. Although lighting calculation can be carried out, there are some shortcomings in the accuracy of lighting calculation results, the return of data and the evaluation of results. Information transmission based on APIT is actually a direct way of information extraction and all process is within BIM system. The advantage of this approach is that only data collection is required, and the process does not require data encoding to form a certain format. However, the current API has a limited set of assemblies, so a lot of programming work is required to deliver all the information in the building design. 


\subsection{Format Conversion of Information Technology (FCIT)}

Information transmission includes two stages: information extraction and information transmission. The internal information transmission of BIM system is through API. In addition to $\mathrm{API}$, there are two other ways of information transmission between internal and external of BIM system, which are intermediate file conversion and common standard conversion. These two methods use "information format conversion" technology to transform information into compatible information formats that can be used both in BIM system and other software. Intermediate file conversion and common standard conversion are the ways to extract information, while the transmission of information needs to be completed with the API. The difference between the two methods lies in whether there are uniform and proprietary norms in format and content. What distinguishes them from direct conversion (APIT) is that FCIT is a way to establish a separate information format file to complete information transmission, which can ensure all information that needed can be extracted.

Using the technology of FCIT, it is necessary to convert the light source information of lamps needs to be converted into a format file in the form of light distribution curve through common standards. At present, the most popular file format standards of the light distribution curves are CIBSE TM-14, EULUMDAT, CIE 102, IESNA LM-63, etc.

IESNA LM-63-1986: IES Recommended Standard File Format for Electronic Transfer Photometric Data is the earliest industry standard for the production of information on luminaires and light source electronic distributions published by the Illumination Engineering Society of North America (IESNA). After three revisions in 1991, 1995 and 2002, the version of 2002 that is currently used have been approved by the American National Standard Institute (ANSI). Then IESNA LM-63-2002 (hereinafter referred to as the IES) has become the only optical file format used in North America. The light distribution curve file of the IES consists of four parts: keywords, initial definitions, direction and position of light sources, angle definitions and luminous intensity arrays (ANSI/IESNA, 2002), which are shown in Table 1.

Table 1 - IES file content and instructions

\begin{tabular}{|c|c|c|}
\hline Composition & Contents in IESNA:LM-63-2002 & Application Description \\
\hline keywords & $\begin{array}{l}\text { - IESNA:LM-63-2002 } \\
\text { - [Keyword 1] Keyword data } \\
\text { - [Keyword 2] Keyword data } \\
\text { - [Keyword 3] Keyword data } \\
\text { - : } \\
\text { - [Keyword n] Keyword data } \\
\text { - TILT=<filename> or INCLUDE or NONE }\end{array}$ & $\begin{array}{l}\text { Describing the lamp and tests information, } \\
\text { including four essential items: test organization } \\
\text { number, name, release date and lamp } \\
\text { manufacturer name; also including lamp product } \\
\text { code, lamp description, light source product code, } \\
\text { light source description and other suggestions }\end{array}$ \\
\hline $\begin{array}{l}\text { initial } \\
\text { definitions }\end{array}$ & $\begin{array}{l}\text { - }<\text { number of lamps }><\text { lumens per } \\
\text { lamp }><\text { candela multiplier }><\text { number of } \\
\text { vertical angles }><\text { number of horizontal } \\
\text { angles }><\text { photometric type }><\text { units } \\
\text { type }><\text { width }><\text { length }><\text { height }> \\
\text { - }<\text { ballast factor }><\text { future use }><\text { input watts }>\end{array}$ & $\begin{array}{l}\text { Basic description of the light source in testing } \\
\text { conditions. } \\
\text { As the ballast factor is not needed in LED light } \\
\text { source, } 1 \text { is adopted and should be maintain } \\
\text { compatibility with the previous version, i.e. LM- } 63 \text {. } \\
\text { Other parameters are set according to the actual } \\
\text { conditions of light source. }\end{array}$ \\
\hline $\begin{array}{l}\text { direction and } \\
\text { position of light } \\
\text { sources }\end{array}$ & $\begin{array}{l}-<\text { lamp to luminaire geometry } \\
-<\text { Number of tilt angles }> \\
-<\text { angles } \\
\text { - }<\text { multiplying factors }> \\
\text { These four lines shall be present if and } \\
\text { only if } \\
\text { TILT=INCLUDE }\end{array}$ & $\begin{array}{l}\text { When TILT=NONE, this part is not considered. } \\
\text { Only when TILT=INCLUDE, this part is needed. } \\
\text { When TILT=<filename>, the tilt information is } \\
\text { expressed in a separate file. }\end{array}$ \\
\hline $\begin{array}{l}\text { angle } \\
\text { definitions and } \\
\text { luminous } \\
\text { intensity arrays }\end{array}$ & $\begin{array}{l}\text { - < vertical angles } \\
\text { - }<\text { horizontal angles } \\
\text { - }<\text { candela values for all vertical angles at } \\
\text { 1st horizontal angle> } \\
\text { - }<\text { candela values for all vertical angles at } \\
\text { 2nd horizontal angle> } \\
\text { - : } \\
\text { - }<\text { candela values for all vertical angles at } \\
\text { last horizontal angle> }\end{array}$ & $\begin{array}{l}\text { This part is the core data, which provides the light } \\
\text { intensity of each group of luminaires at each angle } \\
\text { and uses for calculating the illumination generated } \\
\text { on the object. Each group of light intensity data } \\
\text { contains three variables: horizontal angle, vertical } \\
\text { angle and light intensity. The specific angle is } \\
\text { determined. } \\
\text { In the angle array, the position is expressed in } \\
\text { polar coordinates, the horizontal angle is } \\
\text { expressed in abscissa, and the vertical angle is } \\
\text { expressed in ordinate. The data and angle in the } \\
\text { light intensity array correspond one by one. }\end{array}$ \\
\hline
\end{tabular}


It should be noted that if the information in the file format is not symmetrical with the parsed information in the application program interface of the software, it may also lead to the loss of the extracted information in the transmission process. For example, when IES describes parallel light, three different descriptions can be used, so three IES files with different contents will be obtained. Although the application program interface of lighting software extracts all the information in the file, it will get three different information content parsing results. In the process of information transmission through format transformation, it is easy to fail to extract information content, which causes information loss and affects the results of information processing.

\section{BLI Design Software in BIM System}

At present, to accomplish the development of BLI design software in BIM system by using two major technical means, it should mainly include two parts: a) establish full building lighting information (model) i.e. building or improving BIM system to realize BLI design software(as shown in Figure 2); b) storage and return of lighting information (model) which is used for return and assessment of the information. i.e., building BLI lamp integrated component library, and completing the transmission and calculation of lighting information and results. The building information in Figure 2 refers to building information used for BLI design software in BIM system, such as geometric information, material information, etc. The lighting information refers to the BLI luminaire integrated component library information of the BLI design software. In the BLI design process, lighting is combined with building design. However, in the calculation process, the building information in the BIM system is transferred to the BLI design software. The information return is a process that combining lighting information of BLI design software into the building information of the BIM system.

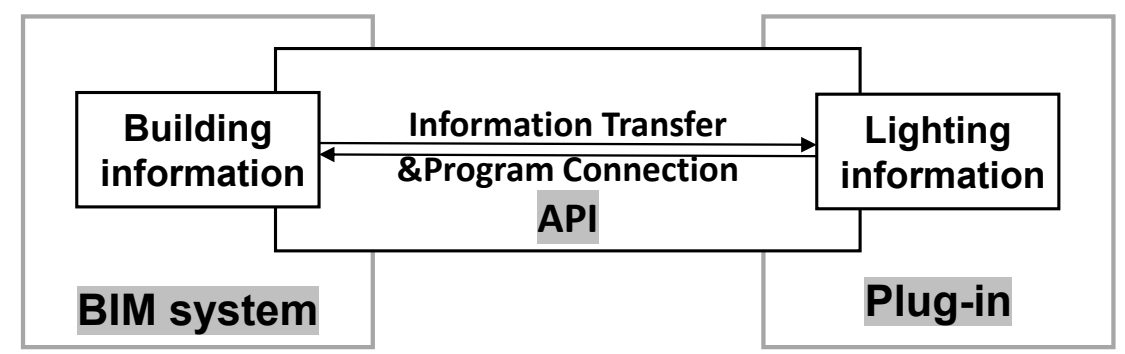

(a) BIM system plug-in form

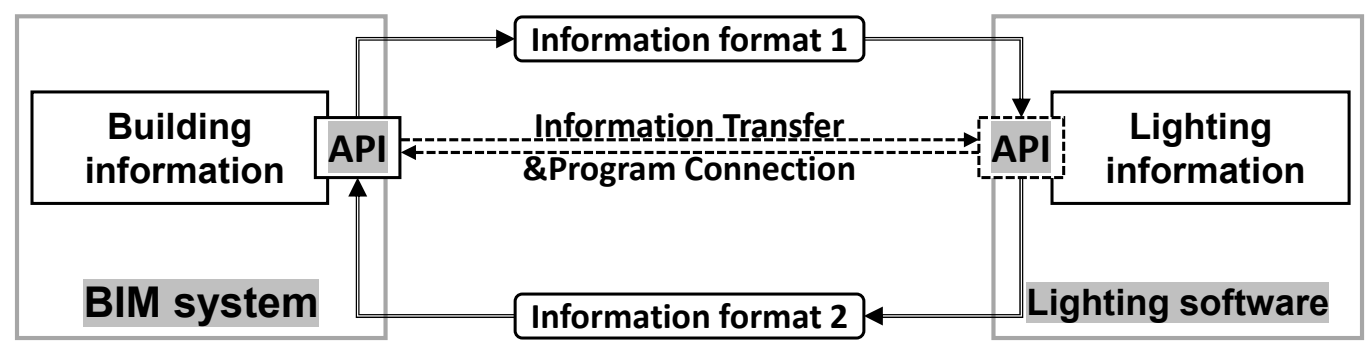

(b) BIM-BLI plug-in form

Figure 2 - General form of BLI design software

\subsection{General form of BLI design software}

The general forms for BLI design software can be summed up in two ways, namely, BIM system plug-in form (Fig. 2a) and the BIM-BLI plug-in form (Fig. 2b).

The so-called BIM system plug-in form (Fig. 2a) uses the technical means of APIT. It is necessary to design the BLI software API which is connected with the API of BIM system. The information transmission is accomplished through the two APIs. At the same time, through this API, programs can be written to expand the functions of BIM system, so that the relevant lighting calculation and analysis functions can be implemented to BIM system. The advantage 
of BIM system plug-in form lies in its better integration with BIM system, but facing a lot of programming work which are restricted by application interface.

The so-called BIM-BLI plug-in form (Fig. 2b) uses both the technical means of APIT and FCIT. The BLI design software connects the BIM system with the lighting software by APIT, transfer information by combination of APIT and FCIT and complete the corresponding analysis by take the advantage of existing lighting software. For functions that are not available in the lighting software, it needs to be programmed in the plug-in. The advantage of this form is that the programming work is relatively small, but due to the multiple conversions of different data formats, information asymmetry or loss may occur. At the same time, lighting software may have problems such as accuracy does not meet the requirements of BLI design software. The technology of FCIT alone cannot be used to develop software, so there are only two forms. It should be noted that the lighting software and plug-ins are independent programs. Their main difference is that the lighting software is a separate software that can be attached to other software alone, but the plug-in is generally attached to the existing software, so there are two different forms of API.

In addition, due to the lack of key hardware in professional lighting software, for developing plug-ins, the connection as shown by the dotted line in Figure $2 \mathrm{~b}$ is currently not available. Therefore, analyse and suggestions are only given on the development of BIM system plug-in (Fig. 1a). Some common suggestions also apply to BIM-BLI plug-in form, but not discussed in this paper.

\subsection{Storage of lighting information (model)}

In Revit software, the storage of information mainly depends on the Revit Family, which is the component of BIM project and the carrier of BIM parameter information. It is a family of light sources, lampshades and their accessories and also is a part of the luminaire integrated component library required by BLI design software. The lighting information should be included not only in the building lighting information established by BLI, but also can be stored separately in order to cooperate with other system software.

Revit Lighting Family has its own function of creating a family. Users can use the template file (a total of nine) with the suffix ".rft" to create a family according to their needs. When creating a Lighting Family, the following processes are required: a) select a suitable light source; b) set the physical parameters of the luminaire according to the distribution mode of the light source information, such as size and material of the lampshade and its accessories; c) set the parameters for light source, such as tilt angle, optical loss factor, initial brightness and initial colour temperature, etc.; d) add IES file, which is part of the luminous flux in the IES file and can be modified in the group editor.

\section{Discussion and suggestions}

The research and development of $\mathrm{BLI}$ design software based on BIM technology mainly depends on two methods, APIT and FCIT, which can be used alternately and complement each other to realize the collaborative design of lighting and building interface, and to realize the design integration and information integration of building and lighting. In view of the objectives mentioned earlier, in combination with the two technical means in Section 2 and the general form of BLI design software with BIM system in Section 3, the following proposals are made:

(1)For the problems described in Section 2.1 APIT mean, it is recommended to link the BLI design software API to the Revit API and allow other software in the BIM system to access the information. At the same time, in the case that the Revit API cannot deliver the required information, it is recommended to re-process the identified information in the BLI design software to obtain the required information, or to supplement the required information by means of FCIT. Therefore, the proposed form of BLI design software is shown in Figure 3. 


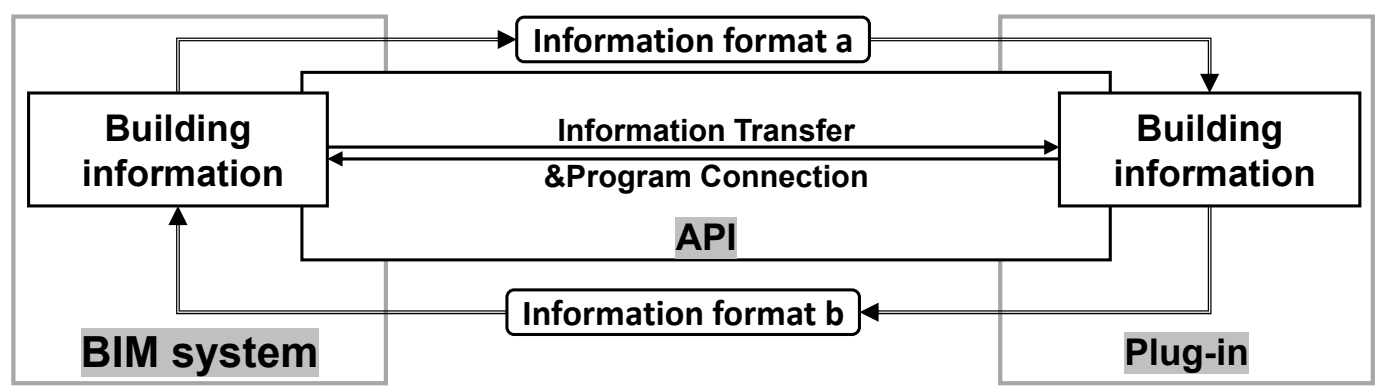

Figure 3 - Proposed form of BLI design software

(2) To use the FCIT to transform information, it is necessary to establish a unified standard professional information integration management platform format. Although the IES format is currently widely used as a light distribution curve format, as described in Section 2.2, not all lighting software recognizes the IES format, and information identification may be inaccurate. In addition, IES itself may also have defects. Therefore, it is recommended to carry out unified requirements and use management for IES-type professional information in lighting software.

(3) The BLI luminaire integrated component library is based on the development of the Revit lighting family, where the light source corresponds to optical information, the lampshade and its accessories correspond to geometric information and material information that including optical, acoustic and thermal information. Specifically, there are three steps:

i. The information in the Revit lighting family is supplemented by the FCIT. For some new optical information on light sources related to the comfort and health of lighting based on the BLI concept, it is recommended to add such information by adding new information to the location analyzed in Section 2.2. To add optical, acoustic and thermal information to the general information of the lampshade and its accessories, it is necessary to convert the added information into computer language as described in Section 2.2. The format of the intermediate file conversion needs to be the type of information format that can be recognized by both the Revit API and the BLI design software API, as shown in Figure 4.

ii. Use the APIT technology to extract the existing direct conversion information in the Revit lighting device family

iii. By Integrating the information from $\mathrm{i}$ and ii, the family creation function of the APIT and the Revit Family which are described in 2.1 are used and complemented each other to establish a BLI luminaire integrated component library.

In addition, for the BLI luminaire integrated component library of BLI design software, besides the Revit family, it can also be implemented in the form of lighting software plug-ins. No matter which form of development is used, BLI luminaire integrated component library can be developed based on the Family of BIM system, and the its database can be saved in the cloud in order to obtain more and updated luminaire data at any time.

(4) Programs can be written in the computer to automatic couple the luminaire to the building interfaces or components. When the building component or interface is assigned to the properties of the lampshade, the luminaire automatically matches the building component or interface in the form of information modularization. Then the function of the APIT means is used to invoke the program written by the computer to realize the combination with the Revit software.

The above suggestions can make the BLI design software finally realizes the organic combination of the LED light source and the luminaire at the computer level, and achieve the goal of collaborative design of lighting and building interface. 


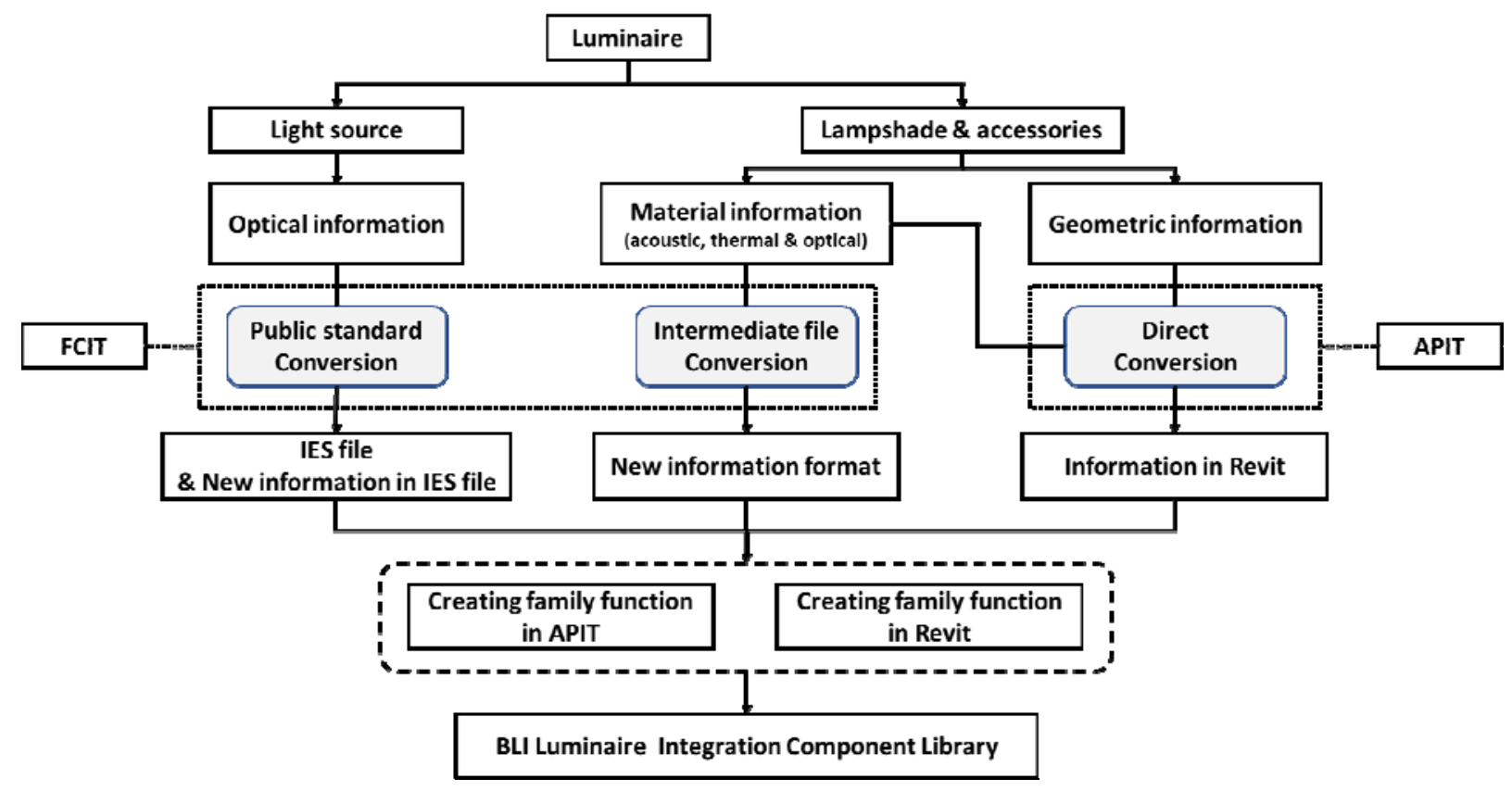

Figure 4 - Information composition and conversion process of lamp integrated component library

\section{Conclusion}

The combination of LED and architecture puts forward new requirements for Building Lighting Integration (BLI) design. This paper is concerned with the development of the BLI design software that based on Building Information Modelling (BIM) technology. Application APIT and FCIT format are believed as the key challenges during this process. The general function and form of the BLI design software to be designed is discussed. The problems in the development process with Revit as the core part were discussed in detail. The relevant suggestions were given with regards to interface design, format conversion of information and development of light component library.

Throughout the BLI design software development proposal, it can be found that the two means of APIT and FCIT are windows, and they are also limitations for research and development of $\mathrm{BLI}$ design software. The more relevant factors of research and development mean that the limiting factor is also more. On the contrary, the more R\&D methods are, the more likely it is to achieve R\&D.

There were a lot of detail work to do in this research. Anyway, the BIM technology applied in LED architectural lighting design may promise to achieve the ideal lighting environment. It probably will become a trend in the field of lighting in the future.

\section{Acknowledgement}

This paper is funded by "13th Five-Year" National Key R \& D Program of China (2018YFC0705100)

\section{References}

HASSAN, N. U., NAEEM, A., PASHA, M. A., JADOON, T. \& YUEN, C. (2015), Indoor Positioning Using Visible LED Lights , ACM Computing Surveys, Vol. 48 No. 2, pp. 1-32.

PÄRN, E. A. \& EDWARDS, D. J. (2017), Conceptualising the FinDD API plug-in: A study of BIM-FM integration, Automation in Construction, Vol. 8011-21.

PEZESHKI, Z. \& IVARI, S. A. S. (2018), Applications of BIM: A Brief Review and Future Outline, Archives of Computational Methods in Engineering, Vol. 25 No. 2, pp. 273-312. 
SANTOS, R., COSTA, A. A., SILVESTRE, J. D. \& PYL, L. (2019), Informetric analysis and review of literature on the role of BIM in sustainable construction, Automation in Construction, Vol. 103221-234.

ZOTKIN, S. P., IGNATOVA, E. V. \& ZOTKINA, I. A. (2016), The Organization of Autodesk Revit Software Interaction with Applications for Structural Analysis , Procedia Engineering, Vol. 153915-919.

ANSI/IESNA 2002. ANSI/IESNA LM-63-02. ANSUIESNA Standard File Format for the Electronic Transfer of Photometric Data and Related Information. United States of America: ANSI/IESNA 